\title{
Papers
}

\section{Burden of illness and suicide in elderly people: case-control study}

\author{
Margda Waern, E Rubenowitz, B Runeson, I Skoog, K Wilhelmson, P Allebeck
}

\begin{abstract}
Objectives To study the association between physical illness and suicide in elderly people.

Design Case-control with illness determined from interviews with relatives of people who committed suicide and with control participants and from medical records.

Setting Gothenburg and two surrounding counties (210 703 people aged 65 years and over).

Participants Consecutive records of people who had committed suicide and had undergone forensic examination (46 men, 39 women) and living control participants from the tax register ( 84 men, 69 women).
\end{abstract}

Main outcome measures Physical illness rated in 13 organ systems according to the cumulative illness rating scale-geriatrics; serious physical illness (organ category score 3 or 4); overall score for burden of physical illness.

Results Visual impairment (odds ratio 7.0, 95\% confidence interval 2.3 to 21.4), neurological disorders (3.8, 1.5 to 9.4), and malignant disease (3.4, 1.2 to 9.8 ) were associated with increased risk for suicide. Serious physical illness in any organ category was an independent risk factor for suicide in the multivariate regression model (6.4, 2.0 to 20.0$)$. When the sexes were analysed separately, serious physical illness was associated with suicide in men $(4.2,1.8$ to $9.5)$ as was high burden of physical illness $(2.8,1.2$ to 6.5). Such associations were not seen in women, possibly because of the small sample size.

Conclusions Visual impairment, neurological disorders, and malignant disease were independently associated with increased risk of suicide in elderly people. Serious physical illness may be a stronger risk factor for suicide in men than in women.

Topic: $271 ; 87 ; 83 ; 161$

\section{Introduction}

Most people who commit suicide late in life suffer from depression. ${ }^{1-4}$ The role of somatic illness is less clear. While somatic illness is often reported in those who attempt ${ }^{56}$ and manage to kill themselves ${ }^{1-4} 7$ in later life, prevalence figures vary from $35 \%{ }^{7}$ to $94 \%{ }^{3}$ There have been few controlled studies. One recent report noted the presence of serious physical illness in $56 \%$ of those who committed suicide compared with $16 \%$ of a control group. ${ }^{8}$ However, only people with recent contact with primary care were included.

We examined the association between illness and suicide using a control group representative of the general elderly population. We hypothesised that suicide would be more likely among people with serious physical illness and tested this hypothesis using the systematic measures of the cumulative illness rating scale-geriatrics. ${ }^{9}$

\section{Methods}

\section{Suicide cases}

We examined reports from 100 consecutive cases of suicide in Scandinavian born people aged $\geqslant 65$ years who underwent necropsy at the Gothenburg Institute of Forensic Medicine. The catchment area included the city of Gothenburg and two adjacent counties (210 703 people aged $\geqslant 65$ in 1994). The reports covered 83 definite cases of suicide and 17 cases in which the cause of death was undetermined but in which the circumstances strongly suggested suicide. According to Statistics Sweden, 11 further cases of suicide were registered in the area during the study period (January 1994 to May 1996) but these were not examined at the institute.

To obtain information on the people who had committed suicide we identified next of kin for 98 of the 100 potential study cases and informed them about the study; 85 agreed to participate. Of the cases of suicide for which we had an informant, 46 were in men (mean age 75 (SD 8) years, age range 65-94) and 39 were in women $(75(7), 65-97)$. The study cases did not differ from the total number of suicides in the catchment area $(\mathrm{n}=111)$ in terms of age $(75(8) \cup 75$ (7)), proportion of women $(46 \% \quad v \quad 45 \%)$, and proportion of definite suicides $(85 \% v 81 \%)$. The proportion in whom traces of antidepressants or lithium were identified at necropsy was similar in both the study group (38\%) and the forensic group (40\%).

\section{Control group}

We randomly selected two people living in the same area and with the same sex and birth year (SD 2 years) as the study case from the tax register. If a person declined to participate we invited another one (up to a maximum of eight per case). We invited 240 people to take part in the study, and 153 (84 men, 69 women)

\section{Section of \\ Psychiatry, Institute of Clinical Neuroscience, \\ Gothenburg \\ University, \\ Sahlgrenska \\ University Hospital, \\ S-413 45 \\ Gothenburg, \\ Sweden \\ Margda Waern \\ research fellow \\ I Skoog \\ associate professor \\ Department of \\ Social Medicine, \\ Gothenburg \\ University \\ E Rubenowitz \\ research fellow \\ K Wilhelmson research fellow \\ P Allebeck \\ professor \\ Department of \\ Psychiatry, \\ St Göran's Hospital, \\ Karolinska Institute, \\ Stockholm, Sweden \\ B Runeson \\ associate professor \\ Correspondence to: \\ M Waern \\ margda.waern@ \\ neuro.gu.se}

bmj.com 2002;324:1355 
Table 1 Serious illness and disability* in elderly people who committed suicide (46 men, 39 women) and living control participants (84 men, 69 women). Figures are numbers (percentage) of people

\begin{tabular}{lccc} 
Organ & Suicides (n=86) & Controls (n=153) & Odds ratio† (95\% $\mathbf{~ I ) ~}$ \\
\hline Heart & $8(9)$ & $15(10)$ & $1.0(0.4$ to 2.5$)$ \\
\hline Vascular & $4(5)$ & $6(4)$ & $1.1(0.3$ to 4.0$)$ \\
\hline Haematopoietic & $1(1)$ & $1(1)$ & $3.2(0.2$ to 53.9$)$ \\
\hline Respiratory & $2(2)$ & $5(3)$ & $0.7(0.1$ to 3.5$)$ \\
\hline Eyes, ears, nose, throat: & & & \\
\hline All & $15(18)$ & $9(6)$ & $6.6(2.4$ to 17.9$)$ \\
\hline Visual impairment & $12(14)$ & $6(4)$ & $7.0(2.3$ to 21.4$)$ \\
\hline Upper gastrointestinal tract & $2(2)$ & $1(1)$ & $6.4(0.5$ to 79.2$)$ \\
\hline Lower gastrointestinal tract & $4(5)$ & $4(3)$ & $3.3(0.7$ to 14.8$)$ \\
\hline Renal & $1(1)$ & $1(1)$ & $2.2(0.1$ to 39.7$)$ \\
\hline Genitourinary & $8(9)$ & $10(7)$ & $3.0(1.0$ to 9.0$)$ \\
\hline Musculoskeletal & $12(14)$ & $24(16)$ & $1.6(0.7$ to 3.9$)$ \\
\hline Endocrine/metabolic & $6(7)$ & $3(2)$ & $2.7(0.6$ to 11.4$)$ \\
\hline Neurological: & $15(18)$ & $10(7)$ & $3.8(1.5$ to 9.4$)$ \\
\hline All & $9(11)$ & $7(5)$ & $2.8(1.0$ to 8.3$)$ \\
\hline Stroke & $9(11)$ & $8(5)$ & $3.4(1.2$ to 9.8$)$ \\
\hline Any malignancy &
\end{tabular}

${ }^{*}$ Rating of 3 or 4 according to cumulative illness rating scale-geriatrics. ${ }^{12}$ Liver category not shown as no individuals had level 3 or 4 conditions in this category.

†Adjusted for age and sex.

participated. Proxy interviews with close informants were carried out for 11 of these because of dementia $(n=10)$ or psychosis $(n=1)$.

\section{Interviews}

The semistructured interview included questions about social situation, life events, past and current mental and physical health, and use of alcohol and illegal and prescription drugs. The interview included psychiatric signs and symptoms in the past month derived from the comprehensive psychiatric rating scale $^{10}$ and questions about symptoms of dementia. ${ }^{11}$ All interviews with relatives of the people who had committed suicide were carried out by a psychiatrist (MW). Interviews with control participants were carried out by a geriatrician (KW), a psychiatric nurse, or a psychiatric occupational therapist, all with long clinical and interview experience.

\section{Rating burden of illness}

We rated physical illness and disability according to the organ specific guidelines of the cumulative illness rating scale for geriatrics ${ }^{9}$ after review of medical records and interview material. We defined serious illness as level 3 (severe/constant disability or "uncontrollable" chronic problems) or 4 (extremely severe illness or severe disability) in any category. The raters made independent ratings for 10 participants. Reliability between raters was good for both total scores $\left(r_{s}=0.99, \mathrm{P}<0.01\right)$ and numbers of ratings at level 3 or 4 $\left(r_{s}=1.00, \mathrm{P}<0.01\right)$. MW used data from interviews and case records to rate mental illness in accordance with the cumulative illness rating scale for geriatrics.

\section{Statistical analysis}

We used logistic regression to calculate odds ratios for committing suicide. Participants in the control group were selected for year of birth and at the time of the interview were slightly older than the people who had committed suicide (78.8 (SD 7.7) v 75.0 (7.7)) because of a time lag between the deaths by suicide and the control interviews. We therefore calculated all odds ratios using age as a covariate. We analysed variables that significantly affected odds ratios in a multivariate logistic regression model (unconditional). We used Fisher's exact test (two tailed) to examine differences in proportions between subgroups within the suicide group or control group and $t$ tests to compare scores. We performed all analyses with SPSS version 10.1 for Windows.

\section{Ethics}

We obtained informed consent from the close informants and people in the control group after they had received oral and written information about the study. A close relative gave proxy consent for people in the control group who had dementia. The research ethics committee at Gothenburg University approved the study.

\section{Results}

\section{Serious physical illness}

Table 1 gives details about serious physical illness or disability by organ category for cases and controls. Risk factors for suicide were impaired vision, neurological disorder, stroke, and malignant disease. Serious physical illness or disability in any organ category was also a risk factor for suicide (table 2).

\section{Sex differences}

Table 2 also shows that among people who committed suicide serious illness or disability was more common in men than in women $(65 \% v 44 \%, \mathrm{P}=0.05)$. Physical illness was associated with a fourfold increase in suicide rate in men. We found no such association in women. We modelled a logistic regression for the entire sample that included age, sex, physical illness, and a sex-physical illness interaction term. Serious physical illness was a significant factor (odds ratio 4.4, 95\% confidence interval 2.0 to 10.0 ) but there was no significant sex interaction $(0.4,0.1$ to 1.4$)$.

We added ratings for each of the 13 somatic categories to yield the overall score for burden of physical illness. Within the suicide group, men had higher overall scores than women (mean score 9.0 (SD

Table 2 Serious illness and disability in elderly people who committed suicide and living control participants, by sex. Figures are numbers (percentage) of people

\begin{tabular}{|c|c|c|c|c|c|c|c|c|c|}
\hline & \multicolumn{3}{|c|}{ Men } & \multicolumn{3}{|c|}{ Women } & \multicolumn{3}{|c|}{ Total } \\
\hline & $\begin{array}{l}\text { Suicides } \\
(n=46)\end{array}$ & $\begin{array}{c}\text { Controls } \\
(\mathrm{n}=84)\end{array}$ & $\begin{array}{l}\text { Odds ratio* } \\
\text { (95\% Cl) }\end{array}$ & $\begin{array}{l}\text { Suicides } \\
(\mathrm{n}=39)\end{array}$ & $\begin{array}{l}\text { Controls } \\
(\mathrm{n}=69)\end{array}$ & $\begin{array}{c}\text { Odds ratio* } \\
\text { (95\% Cl) }\end{array}$ & $\begin{array}{c}\text { Suicides } \\
(\mathrm{n}=85)\end{array}$ & $\begin{array}{l}\text { Controls } \\
(n=153)\end{array}$ & $\begin{array}{c}\text { Odds ratio† } \\
(95 \% \text { Cl) }\end{array}$ \\
\hline Any serious physical condition $\dagger$ & $30(65)$ & $32(38)$ & $4.2(1.8$ to 9.5$)$ & $17(44)$ & $28(41)$ & $2.1(0.8$ to 5.3$)$ & $47(55)$ & $60(39)$ & $3.0(1.6$ to 5.5$)$ \\
\hline Overall physical burden score $>10 \ddagger$ & $19(41)$ & $23(27)$ & $2.8(1.2$ to 6.5$)$ & $4(10)$ & $21(30)$ & $0.4(0.1$ to 1.4$)$ & $23(27)$ & $44(29)$ & $1.4(0.7$ to 2.7$)$ \\
\hline Any serious mental condition $\dagger$ & $41(89)$ & $6(7)$ & $99.8(28.5$ to 349.0$)$ & $35(90)$ & $9(13)$ & 61.6 (16.7 to 227.1) & $76(89)$ & $15(10)$ & 77.0 (31.4 to 189.0$)$ \\
\hline
\end{tabular}

${ }^{*}$ Adjusted for age and sex.

†Level 3 or 4 according to cumulative illness rating scale-geriatrics. ${ }^{12}$

tSum of ratings for somatic categories. 
Table 3 Multivariate logistic regression analyses (unconditional) between physical disorder variables, sociodemographic variables, history of depression, and suicide in 130 men and 108 women aged $\geqslant 65$ years

Odds ratio* $(95 \% \mathrm{Cl})$

\begin{tabular}{lc}
\hline Interpersonal conflicts & Odds ratio* $\mathbf{9 5 \%} \mathbf{C I})$ \\
\hline History of major depression & $19.4(5.7$ to 66.3$)$ \\
\hline Visual impairment & $15.9(5.6$ to 44.9$)$ \\
\hline Malignancy & $11.4(2.4$ to 54.5$)$ \\
\hline Neurological disorder & $4.7(1.2$ to 18.2$)$ \\
\hline
\end{tabular}

${ }^{*}$ Adjusted for age, sex, and overall burden of physical illness.

Table 4 Multivariate logistic regression analyses (unconditional) between any serious physical illness, sociodemographic variables, history of depression, and suicide in 130 men and 108 women aged $\geqslant 65$ years

Odds ratio* $(95 \% \mathrm{Cl})$

\begin{tabular}{lc}
\hline Education beyond mandatory & $0.4(0.2$ to 1.0$)$ \\
\hline Interpersonal conflicts & $20.9(6.2$ to 70.0$)$ \\
\hline History of major depression & $13.4(5.2$ to 34.5$)$ \\
\hline Any serious physical illness & $6.4(2.0$ to 20.0$)$ \\
\hline
\end{tabular}

*Adjusted for age, sex, and overall burden of physical illness.

$5.0)$ v $6.8(\mathrm{SD} 3.9) ; \mathrm{df}=83, \mathrm{P}=0.03,95 \%$ confidence interval for difference 0.2 to 4.1 ). There was no sex difference in the control group (8.0 (SD 4.6) in men $v 8.4$ (SD 4.5) in women; $\mathrm{df}=151, \mathrm{P}=0.6,-1.9$ to 1.0 ). High overall score $(>10)$ was associated with an almost threefold increase in suicide rate in men (table 2). We found no association in women. When we entered a sex-high illness burden interaction term into the regression model along with age, sex, and high overall burden of illness, we found that high overall burden of illness was significantly associated with suicide (odds ratio $2.7 ; 1.2$ to $6.2, \mathrm{P}=0.02$ ) and there was a significant sex interaction $(0.2 ; 0.04$ to $0.6, \mathrm{P}=0.009)$.

\section{Mental illness}

Mental illness was strongly associated with suicide (table 2). Seventy six (89\%) of the people who committed suicide and $15(10 \%)$ of the control group had a level 3 or 4 rating for the mental illness category. Mood disorders (any subtype) were highly prevalent in those who committed suicide, regardless of physical health status (39 (83\%) had serious physical illness and mood disorder compared with $31(82 \%)$ who had mood disorder only, $\mathrm{P}=1.00$ ). We studied order of appearance of physical disorder and mood disturbance in the suicide subgroup with both these disorders $(n=39)$. The first episode of depression developed after the onset of physical illness in $18(46 \%)$. The opposite was observed in $20(51 \%)$. Depression and chronic pain seem to have developed simultaneously in one woman.

\section{Multivariate regression models}

We entered the disorders that were associated with suicide in the univariate analyses in a multivariate logistic regression model. Covariates included loss of parent or parents before the age of 18 years due to adoption, divorce, or death, education level, marital status, interpersonal conflict, and history of major depression. Significant associations remained for all three somatic disorders (table 3). A second multivariate regression showed that serious physical illness in any organ category was independently associated with suicide (table 4).

\section{Discussion}

To our knowledge this is the first population based case-control study using systematic measures to examine the association between physical disorder and suicide in elderly people. Visual impairment, neurological disorders, and malignant disease were independently associated with suicide in elderly people.

\section{Limitations}

A main limitation was the low number of individuals in some subgroups, which is reflected in large confidence intervals. Secondly, the participation rate in the control group was not high (64\%). Only 13 of the 87 we asked to take part said they declined participation because of poor health, but we have no objective information regarding their health status of non-participants. Data sources for cases and controls were asymmetric. Informants may have exaggerated health problems in an attempt to understand why their relatives had committed suicide. Alternately, they could have been unaware of some afflictions. Interviewers and raters were aware of the case or control status of the participants because masking was not possible. However, medical records and prescription data comprised the main basis for scoring, and these data were registered before the suicide. Finally, caution must be exercised in generalising these findings to other settings. Rates of suicide in Sweden are at an intermediate level on an international scale. The rate for women ( $\geqslant 65$ years) in the study area was identical to the national rate $(19 / 100000)$. The corresponding figure for men $(38 / 100000)$ was somewhat lower than the national rate $(46 / 100000)$.

\section{Main findings}

Serious physical illness was independently associated with suicide. However, physical illness seemed to be a stronger predictor in men. We found no such association in women, possibly because of small numbers, though there may be a real sex difference. The proportions of men $(65 \%)$ and women $(44 \%)$ with serious physical illness were similar to those reported in elderly men and women who committed suicide in Finland (55\% and 31\%). ${ }^{12}$

Impaired vision was a predictor of suicide in our study. While visual impairment has been shown to be associated with depression in later life ${ }^{13}$ few studies have explored a possible link with suicide. One study that did found no association. ${ }^{14} \mathrm{~A}$ more recent report noted an association between visual impairment and suicidal ideation. ${ }^{15}$ Neurological disorder was associated with suicide in our study, paralleling findings from register studies on mixed age populations. ${ }^{16}$ Infirmity in this category was mainly due to stroke. While the association between stroke and depression is well documented, the association between stroke and suicide is less clear. One recent review found no increased risk of suicide in people with cerebrovascular disorders. ${ }^{17}$ One register study found a decreased risk of suicide among people who had had a stroke. ${ }^{18}$ Another found increased suicide mortality in elderly women with stroke but not in men..$^{19}$ The number of people with stroke in our study was too low to test for sex differences.

We observed an increased rate of suicide in people with ongoing malignant disease, which agrees with 


\section{What is already known on this topic}

Physical illness is a common antecedent to suicide in elderly people, though prevalence figures vary widely from $34 \%$ to $94 \%$

The risk of suicide associated with physical illness is unclear because there are few controlled studies

A recent report noted serious physical illness in $56 \%$ of those who committed suicide compared with $16 \%$ of a control group

\section{What this study adds}

Visual impairment, neurological disorder, and malignant disease were all independently associated with suicide in elderly people

Both serious physical illness and high overall burden of illness are stronger risk factors in men than in women

results of studies of mixed age $\mathrm{e}^{20}$ and elderly ${ }^{18}$ populations. Cardiovascular disease and musculoskeletal disorders have been reported as common among elderly people who committed suicide. ${ }^{2}$ The case-control design allowed us to show that these disorders were not risk factors for suicide as they were also prevalent in the control group.

While somatic illness was an independent risk factor for suicide, the strength of the association was modest compared with that for mental disorder. Many elderly people who commit suicide consult their doctor a short time before their death, ${ }^{21}$ but many fail to communicate their despair. We have recently shown that relatives observed suicidal feelings twice as frequently as doctors, and doctors were less likely to discuss suicidal feelings with patients in poor physical health. ${ }^{22}$ Further research should focus on the detection and treatment of depression and suicidal ideation in the context of physical disease.

We thank the informants and the control participants who made this study possible. We thank Dr Mark Miller for instruction regarding the cumulative illness rating scale; Eva Johansson and Christina Andersson for the interviews; Marina Johansson and Eva Thydén for technical support; Walter Sundh and Derek Eder for statistical assistance; and Professor Jan Beskow for valuable advice. We also thank Professor Kerstin Boström and Dr Adam Berkovitz at the Gothenburg Department of Forensic Medicine.

Contributors: MW formulated the hypothesis, undertook the literature search, designed the study protocol, interviewed the relatives, supervised the interviews with control participants, reviewed case records and interview data, analysed and interpreted data, and wrote the paper. ER reviewed case records, analysed data, with emphasis on rating of illness burden, contributed to the interpretation of results, discussed core issues from an epidemiological point of view, and helped to edit the paper. BR participated in the study design, advised on ethical issues, and helped to interpret the data, especially psychiatric diagnostics, and edit the paper. IS participated in the study design and in the interpretation of data and helped to write and edit the paper. KW took part in data collection, suggested statistical analyses, assisted in the interpretation of results, and helped to edit the paper. PA suggested the study design, participated in data interpretation, and edited the paper. MW is guarantor.

Funding: Swedish Council for Social Research (grants 40042, 0914), Swedish Medical Research Council (grant no K-11337), Swedish Foundation for Health Care Science and Allergy Research (V98 226), Gothenburg Medical Society, Lundbeck Foundation, Söderström König Foundation, and Yhlen's Foundation.

Conflict of interest: None declared.

1 Barraclough BM. Suicide in the elderly. In: Kay DKW, Walk A, eds. Recent developments in psychogeriatrics. Ashford, Kent: Headley, 1971:87-97.

2 Clark DC, Clark SH. Suicide among the elderly. In: Böhme K, Freytag R, Wächter C, Wedler H, Regensburg S, eds. Suicidal behavior: the state of the art. Proceedings of the XVI Congress of the International Association for Suicide Prevention. Regensburg: Roderer, 1993:161-4.

3 Carney SS, Rich CL, Burke PA, Fowler RC. Suicide over 60: the San Diego study. J Am Geriatr Soc 1994;42:174-80.

4 Henriksson MM, Marttunen MJ, Isometsä ET, Heikkinen ME, Aro HM, Kuoppasalmi KI, et al. Mental disorders in elderly suicide. Int Psychogeriatr 1995; 7:275-86.

5 Lyness JM, Conwell Y, Nelson JC. Suicide attempts in elderly psychiatric inpatients. J Am Geriatr Soc 1992;40:320-4

6 Hepple J, Quinton C. One hundred cases of attempted suicide in the elderly. Br J Psychiatry 1997;171:42-6.

7 Sainsbury P. Suicide in London. Maudsley monographs. No 1. London: Chapman and Hall, 1955.

8 Conwell Y, Lyness JM, Duberstein P, Cox C, Seidlitz L, DiGiorgio A, et al. Completed suicide among older patients in primary care practices: a controlled study. J Am Geriatr Soc 2000;48:23-9.

9 Miller MD, Paradis CF, Houck PR, Mazumdar S, Stack JA, Rifai AH, et al. Rating chronic medical illness burden in geropsychiatric practice and research: application of the cumulative illness rating scale. Psychiatry Res 1992;41:237-48

10 Åsberg M, Montgomery SA, Perris C, Schalling D, Sedvall G. A comprehensive psychopathological rating scale. Acta Psychiatr Scand Suppl 1978;5-27.

11 Skoog I, Nilsson L, Palmertz B, Andreasson LA, Svanborg A. A population-based study of dementia in 85-year-olds. $N$ Engl J Med 1993;328:153-8

12 Heikkinen ME, Lönnqvist JK. Recent life events in elderly suicide: a nationwide study in Finland. Int Psychogeriatr 1995:7:287-300.

13 Kennedy GJ, Kelman HR, Thomas C, Wisniewski W, Metz H, Bijur PE Hierachy of characteristics associated with depressive symptoms in an urban elderly sample. Am J Psychiatry 1989;146:220-5.

14 Stensman R, Sundquist-Stensman U-B. Physical disease and disability among 416 suicide cases in Sweden. Scand J Soc Med 1988;16:149-53.

15 Forsell Y, Jorm AF, Winblad B. Suicidal thoughts and associated factors in an elderly population. Acta Psychiatr Scand 1997;95:108-11.

16 Stenager E, Stenager E. Suicide in patients with neurological disorders. In: Stenager E, Stenager E, eds. Disease, pain and suicidal behavior. Binghamton, NY: Haworth Medical Press, 1998:31-49.

17 Harris EC, Barraclough BM. Suicide as an outcome for medical disorders. Medicine 1994;73:281-96.

18 Grabbe L, Demi A, Camann MA, Potter L. The health status of elderly persons in the last year of life: a comparison of deaths by suicide, injury and natural causes. Am J Public Health 1997;87:434-7.

19 Stenager EN, Madsen C, Stenager E, Boldsen J. Suicide in patients with stroke: epidemiological study. BMJ 1998;316:1206.

20 Allebeck P, Bolund C. Suicides and suicide attempts in cancer patients Psychol Med 1991;21:979-84.

21 Harwood DMJ, Hawton K, Hope T, Jacoby R. Suicide in older people: mode of death, demographic factors, and medical contact before death. Int J Geritatr Psychiatry 2000;15:736-43.

22 Waern M, Beskow J, Runeson B, Skoog I. Suicidal feelings in the last year of life in elderly persons who commit suicide. Lancet 1999;354:917-8.

(Accepted 19 December 2001) 